\title{
Effects of Multiple Factors on Water Hammer Induced by a Large Flow Directional Valve
}

\author{
Yaoyao Liao 1, 2,* - Zisheng Lian ${ }^{1,2}$-Jiling Feng 3 - Hongbing Yuan ${ }^{1,2}$ - Ruihao Zhao ${ }^{1,2}$ \\ 1 Taiyuan University of Technology, College of Mechanical Engineering, China \\ 2 Shanxi Key Laboratory of Fully Mechanized Coal Mining Equipment, China \\ 3 Manchester Metropolitan University, School of Engineering, UK
}

The flow gain of the large flow poppet directional valve presently used on hydraulic-powered support is large, so water hammer occurs easily when the poppet valve closes. Thus, the hydraulic system, its components, and human safety are seriously threatened. To solve this problem, a plane-sealed large flow directional valve with different throttle windows, which must be taken into consideration when the mathematical model is established, is designed. The effects of spring stiffness and the shape of the throttle window on the hydraulic shock induced by the valve are analysed with the combination of simulation and experiments. It is obvious that the bigger the spring stiffness is, the greater the water hammer is produced. When the spring stiffness continues to increase, the valve becomes instable and causes much stronger water hammer. The area gains of the valves with different throttle windows (round type, triangular type, rectangle combined type) are different, and the corresponding instances of water hammer differ accordingly. Compared with the common round throttle window, the triangular window produces the lowest shock. Furthermore, the effects of the closing time and the type of control curve of the main valve on the water hammer are explored. It is helpful for the proportional control of the large flow water directional valve in the future. This study provides valuable references for the design of the large flow water valve and the corresponding control of water hammer.

Keywords: large flow directional valve, hydraulic shock, throttle window, hydraulic support

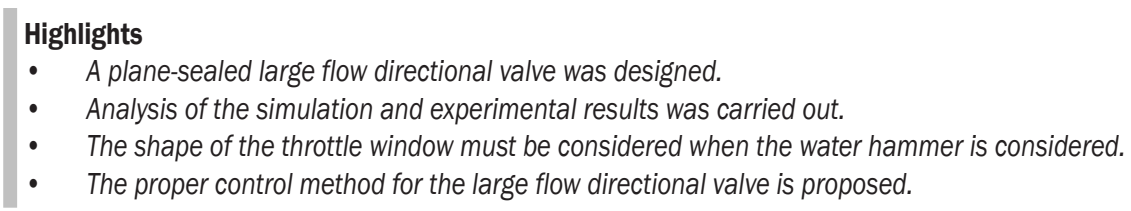

\section{O INTRODUCTION}

Hydraulic support is the most critical supporting equipment. It supports the roof and is coupled with the surrounding rocks in the coal mine, not only providing safe space for workers and equipment but also making lifting, dropping, pushing, and moving actions [1]. Water has been gradually adopted as the transmission medium instead of the traditional emulsion (which easily pollutes the underground water) because of its flame retardant property and environmentally friendly and economical characteristics [2], but its low compressibility and large pressure stiffness easily cause hydraulic shock, which may lead to serious risks to the hydraulic system, its components, and human safety [3]. Fig. 1 shows the corresponding damaged hydraulic cylinders of the hydraulic support. Moreover, to meet the moving time requirement, there is an urgent need for greater mining height hydraulic support and the $1000 \mathrm{l} / \mathrm{min}$ large flow directional valve because of the thick coal seams that have been discovered in recent years [4]. The increasing flow will make water hammer more serious, so finding methods to reduce water hammer is essential.
In general, an accumulator can be used to suppress water hammer, but many parameters affect its effect [5], so it increases the complexity of the hydraulic system. It is known that water hammer is related to the characteristics of the pipeline and the directional valve, but the pipeline is very long and laid in a complex structure in the coal mine, so it is exceptionally difficult to optimize or change

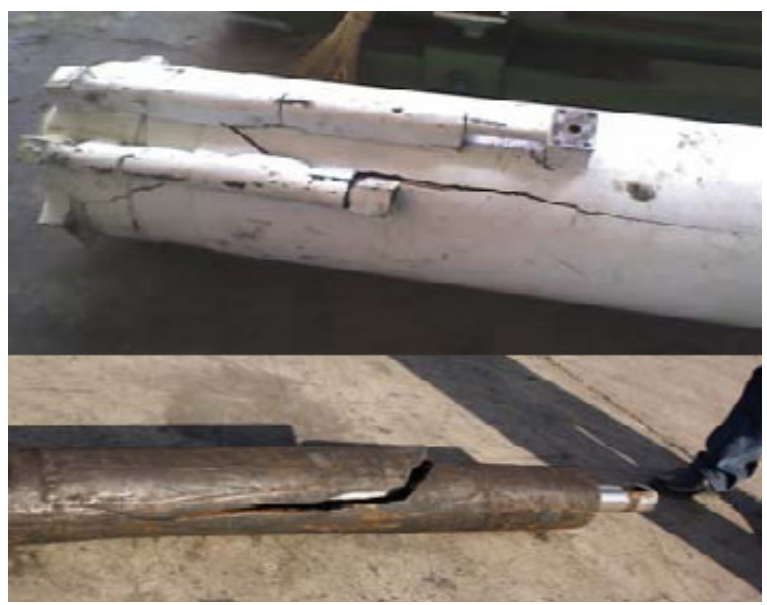

Fig. 1. The damaged hydraulic cylinders 
the pipeline. However, it is relatively much easier to carry out the optimization of the directional valve. In general, there are two factors of the hydraulic valve leading to water hammer: one is the oscillation of the spool [6] and [7], and the other is the rapid closure of the valve [8] to [10]. Many scholars have studied this problem. Kou et al. [11] proposed a method to reduce the water hammer based on multiple section velocity adjustments of the valve in a drainage system. Yao et al. [12] pointed out that water hammer is due to the rapid opening and closing of the valve and proposed a scheme to delay the process, analysing the water hammer with the multi-scale asymptotic method. Wan and $\mathrm{Li}$ [13] analysed the influence of the operational time differences between the pump and the valve on transient pressure, using the method of characteristics. Kaliatka et al. [14] simulated a case of water hammer in a water-heating system with RELAP5 software, pointing out that the water hammer is due to the rapid closing of the check valve. Karadžić et al. [15] observed the cavitation and the separation of water column induced by the switching process of the valve and studied their effects on water hammer. Yang et al. [16] investigated the water hammer phenomenon of a tank-pipeline-valve system using three-dimensional computational fluid dynamics and studied the effects of time step on the accuracy of water hammer. Amirante et al. [17] and Lisowski [18] and Filo and [19] designed the new valve port to meet the high pressure and large flow proportional valve.

The abovementioned research studies all decrease the water hammer by delaying the valve-closing process. In fact, this is to reduce the flow gain when the valve is opening or closing. However, the shape of the throttle window is seldom considered when a model is established. In this paper, the mathematical model of the throttle window is considered. On this basis, the effects of the shape of the throttle window, the spring stiffness and the control form of the directional valve on the water hammer are researched. The study of this paper is not only helpful for the design and optimization of the large flow directional valve used on the hydraulic support but also provides some significant references for the proportional control of the large flow water directional valve in the future.

\section{STRUCTURE AND THE MODEL}

\subsection{Working Principle}

Current large flow high-water-based directional valves are all designed with the poppet structure, and

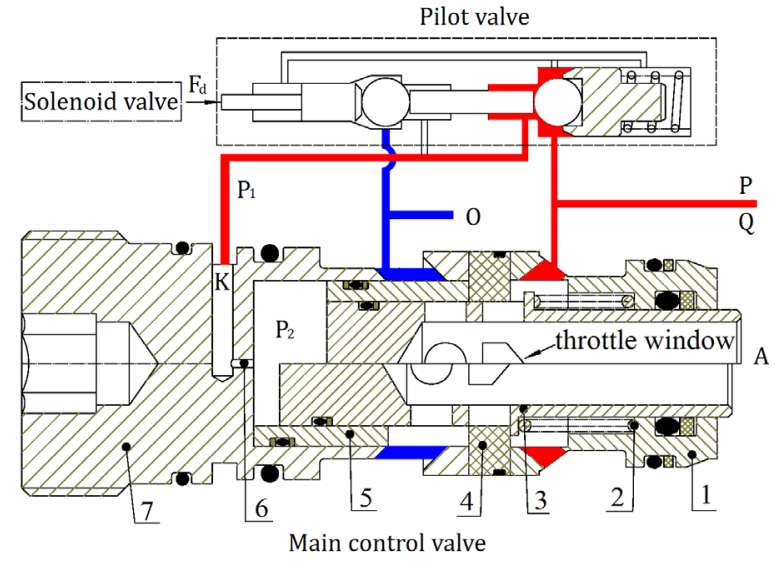

Fig. 2. The new designed $1000 \mathrm{l} / \mathrm{min}$ large flow electro-hydraulic directional valve; 1-inlet valve sleeve, 2-spring,

3-plane sealed valve spool, 4-seat, 5-return valve spool, 6-fixed orifice, 7-return valve sleeve

the maximum flow capacity is $400 \mathrm{l} / \mathrm{min}$. However, the proposed valve dimensions are bigger while the rated flow increases to $1000 \mathrm{l} / \mathrm{min}$, which results in a larger area subjected to pressure. If the poppet structure will continue to be used, the strength of the seat may not be sufficient because of the much larger sealing force on the sharp corner of the seat. Moreover, the flow gain of the poppet valve is big, so water hammer occurs easily when the poppet valve closes rapidly. To solve this problem, a planesealed valve with a different kind of throttle window is designed. The overlap of the valve is zero ideally, but in reality, there is a very small overlap that is caused by the mis-machining tolerance. The leakage of the valve port is not taken into consideration here. The new valve has two advantages. One is that the contact stress on the sealing band of the seat is much lower because of the large plane sealed area, and the other is that the water hammer is lower by different throttle windows, which have different flow gains. Fig. 2 shows the detailed structure of the new large flow directional valve. P represents the inlet channel, where the high-pressure liquid is supplied. O stands for the outlet channel, where the low-pressure liquid returns back. The upper half of the main control valve in Fig. 2 is the working state, and the lower half is the off state. The main control valve is controlled by the pilot valve. When the solenoid valve is powered, the pilot valve opens due to the output force of the solenoid valve, $F_{d}$. The pressure liquid flows to port $\mathrm{K}$, which is the control port of the large flow valve and flows through the fixed hydraulic orifice to the main control valve chamber. Then the valve spool moves to the right. Then the large flow valve begins to 


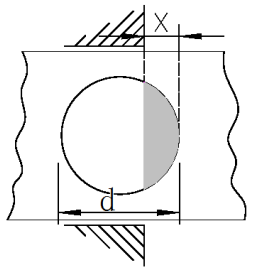

(a) round

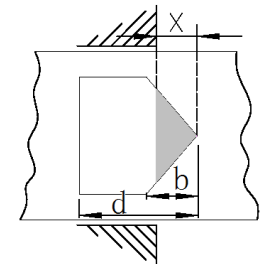

(b) triangular

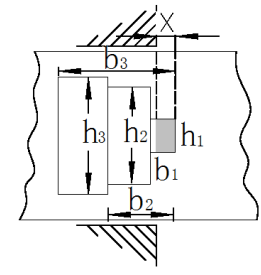

(c) rectangle combined

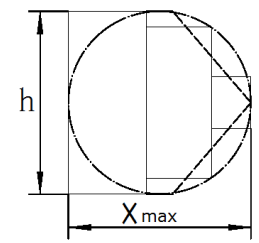

(d) relation of the three windows

Fig. 3. The three different throttle windows and the corresponding relationship

work, supplying liquid from P to A. When the power of the solenoid valve is off, the pilot valve and the main control valve return to the initial off state by the compressed springs.

\subsection{Mathematic Model}

\subsubsection{Area Gain of the Throttle Window}

The operation of the directional valve will cause hydraulic shock, which is positively correlated with the flow gain of the throttle window. The flow equation of the throttle window is:

and the flow gain is:

$$
Q_{x}=C_{q} A(x) \sqrt{\frac{2 \triangle p}{\rho}},
$$

$$
K_{q x}=\frac{\partial Q_{x}}{\partial x}=C_{q} \sqrt{\frac{2 \triangle p}{\rho}} \times \frac{d A(x)}{d x},
$$

where, $C_{q}$ is the flow coefficient of the throttle window, $A(x)$ is the flow area, $\Delta p$ is the pressure difference of the throttle port, $x$ is the opening of the valve port. $Q_{x}$ is the flow of the throttle window, and $K_{q x}$ is the flow gain.

Obviously, the flow gain is proportional to the area gain of the valve port, so the design of the throttle window is critical for controlling the hydraulic shock. The innovation here is that the traditional poppet valve is changed into a plane-sealed valve which is shown in Fig. 2. When the plane-sealed valve opens, the flow area is an annular area that is much larger than the area of the throttle window under the same opening, and the throttling effect mainly occurs near the throttle window. Therefore, the throttle window is used to control the hydraulic shock. Fig. 3 shows three designed throttle windows: round shaped, triangle shaped, and rectangle-combined shape. What needs to be noted here is that the area of the three throttle windows is equal to ensure the maximum flow. In addition, the maximum width $h$ and the maximum opening $x_{\max }$ are the same. The relationship of the three throttle windows is shown in Fig. $3 \mathrm{~d}$.
The flow gain is proportional to the area gain of the throttle window according to Eq. (2). The area gains of the three throttle windows are calculated as follows:

(1) The round window:

The throttle area is:

$$
A_{1}(x)=\frac{d^{2}}{4}\left[\arccos \left(1-\frac{2 x}{d}\right)-2\left(1-\frac{2 x}{d}\right) \sqrt{\frac{x}{d}-\left(\frac{x}{d}\right)^{2}}\right] .
$$

The area gain is:

$$
\frac{d A_{1}(x)}{d x}=2 \sqrt{x(d-x)}
$$

(2) The triangle window:

The throttle area is:

$$
A_{2}(x)=\left\{\begin{array}{lc}
\frac{d}{2 b} x^{2} & (x<b) \\
d x-b d / 2 & (b<x<d)
\end{array} .\right.
$$

The area gain is:

$$
\frac{d A_{2}(x)}{d x}=\left\{\begin{array}{lr}
\frac{d}{b} x & (x<b) \\
d & (b<x<d)
\end{array} .\right.
$$

(3) The rectangle combined window

The throttle area is:

$A_{3}(x)=\left\{\begin{array}{lc}h_{1} x & \left(x \leq b_{1}\right) \\ h_{2} x+b_{1} h_{1}-b_{1} h_{2} & \left(b_{1}<x \leq b_{2}\right) .(7) \\ h_{3} x-b_{1}\left(h_{2}-h_{1}\right)-b_{2}\left(h_{3}-h_{2}\right) & \left(b_{1}<x \leq b_{2}\right)\end{array}\right.$

The area gain is:

$$
\frac{d A_{3}(x)}{d x}=\left\{\begin{array}{lr}
h_{1} & \left(x \leq b_{1}\right) \\
h_{2} & \left(b_{1}<x \leq b_{2}\right) . \\
h_{3} & \left(b_{1}<x \leq b_{2}\right)
\end{array}\right.
$$

Fig. 4 shows the area gain curves of the three throttle windows. In the small opening stage, it is observed that the area gain of the round-shaped throttle window is the biggest, followed by those of 
the rectangle-combined-shaped and triangle-shaped windows.

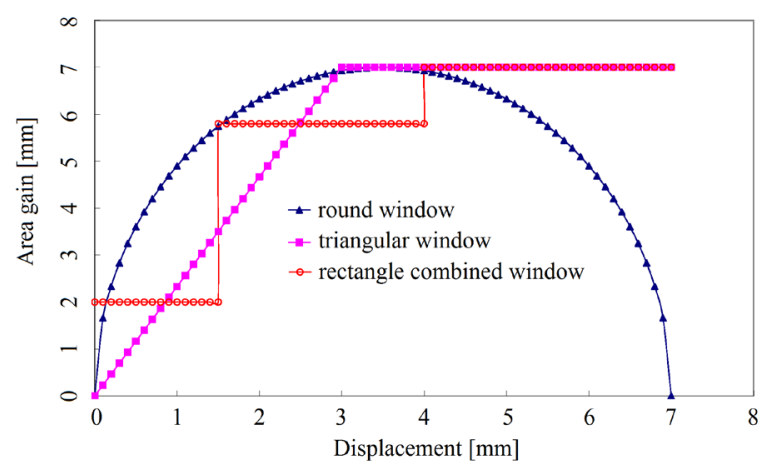

Fig. 4. Flow gain of the three different valves

\subsubsection{Mathematic Model of the System}

The basic motion equations, flow equations, and continuity equations are as follows:

Motion equations of the pilot valve:

$m_{1} \frac{d^{2} x_{1}}{d t^{2}}+c_{f 1} \frac{d x_{1}}{d t}+k_{1} x_{1}=F_{d}-F_{p 1}-F_{w 1}-F_{10}$.

Flow rate of the pilot valve

$$
q_{1}=C_{q 1} A_{p 1} \sqrt{2\left(p-p_{1}\right) / \rho} .
$$

Flow rate of the fixed orifice

$$
\begin{gathered}
q_{2}=C_{q 2} A_{p 2} \sqrt{2\left(p_{1}-p_{2}\right) / \rho}, \\
q_{1}=q_{2} .
\end{gathered}
$$

Motion equations of the main control valve

$m_{2} \frac{d^{2} x}{d t^{2}}+c_{f 2} \frac{d x}{d t}+k_{2} x=F_{p 2}-F_{w 2}-F_{20}-F_{m}$.

Flow continuity of the main control valve

$$
\begin{gathered}
q_{1}-\frac{V_{1}}{\beta} \frac{d p_{2}}{d t}=A_{1} \frac{d x}{d t}, \\
Q=C_{q} A(x) \sqrt{2\left(p-p_{z}\right) / \rho} .
\end{gathered}
$$

The fluid transfers in the pipeline and the foundation equations are as follows:

The momentum equation:

$$
-\frac{1}{g} \frac{\partial V}{\partial t}=\frac{\partial H}{\partial l}+\frac{f}{D} \frac{V^{2}}{2 g}+\frac{\partial}{\partial l}\left(\frac{V^{2}}{2 g}\right) .
$$

The continuity equation:

$$
\frac{\partial H}{\partial t}+V \frac{\partial H}{\partial l}+\frac{a^{2}}{g} \frac{\partial V}{\partial l}-V \sin \theta=0,
$$

$$
p=\rho g H .
$$

All the symbols of the equations above are listed in Table 1. Then Eqs. (17) and (18) can be solved using the characteristic line method [11]. It is noted that the cross-section areas of all the pipes are the same.

\section{EXPERIMENTAL TESTS}

Three valve spools with different throttle windows are designed and manufactured for testing the hydraulic shock induced by the large-flow directional valve. The corresponding experimental principle is shown in Fig. 5. It is difficult to find a $1000 \mathrm{l} / \mathrm{min}$ large flow pump for the $1000 \mathrm{l} / \mathrm{min}$ large flow directional valve, so a large accumulator was used to provide the required flow. However, the accumulator can absorb pressure shock in many cases, so a check valve is used to avoid this problem. The pressure sensor and the displacement sensor are used to test the pressure fluctuations and the valve displacement, respectively. A data acquisition computer is used to obtain the experimental data, and the flow is tested with a flow gauge. The throttle valve is used to adjust the back pressure of the valve. Fig. 6 shows the corresponding test benches. All the tests are carried out at $15 \mathrm{MPa}$. Each final testing result is the average value of three testing groups.

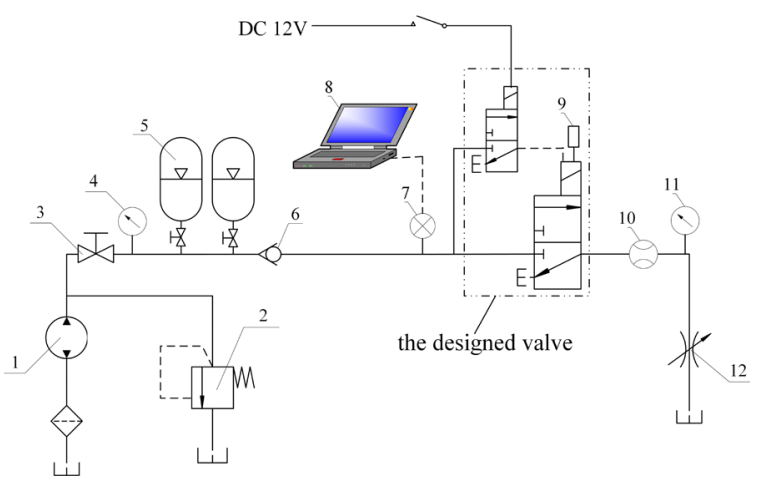

Fig. 5. The experimental principle; 1-pump, 2-relief valve, 3-shut-off valve, 4 and 11-pressure gauge, 5-accumulator, 6-check valve, 7-pressure sensor, 8-data acquisition computer, 9-displacement sensor, 10-flowmeter, 12-throttle valve

\section{ANALYSIS OF THE RESULTS}

\subsection{Effects of Spring Stiffness}

Compared with the huge pressure force on the valve, the spring force, determined by the spring stiffness, is so small that it has little effect on the opening speed of the valve, but it affects the closing speed of the 

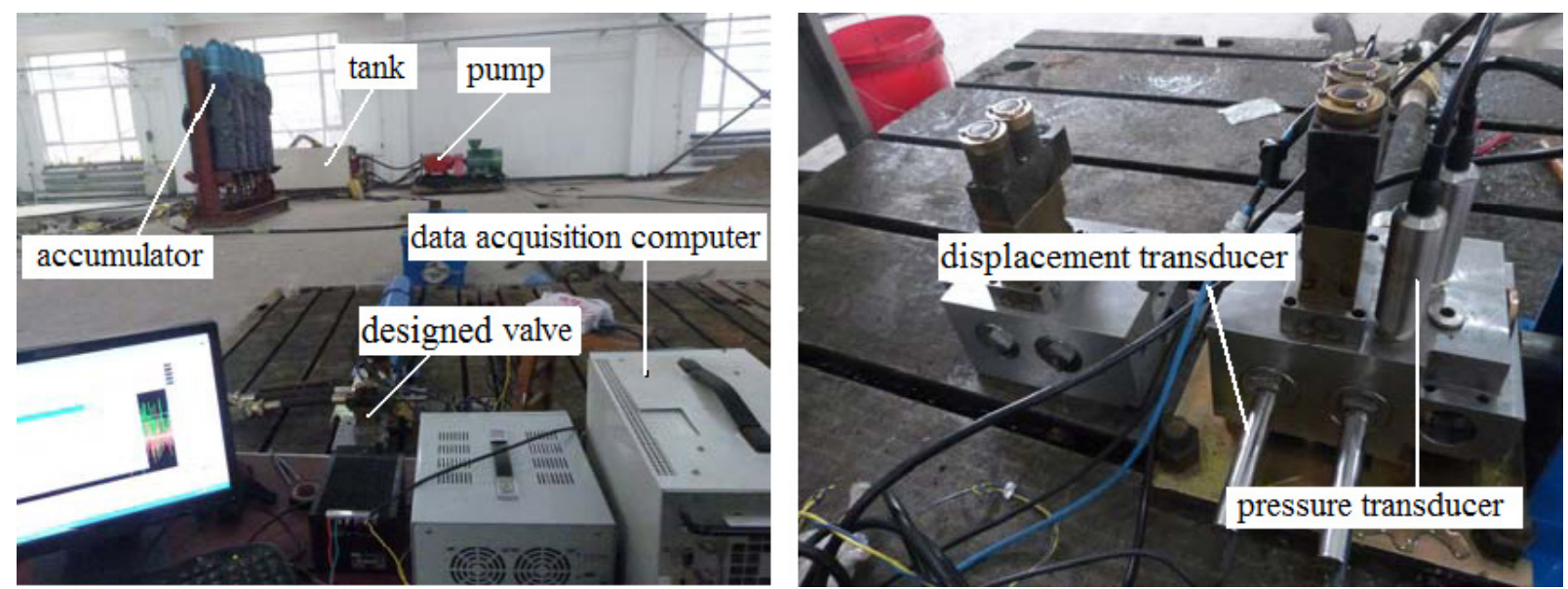

Fig. 6. The experimental setup

valve, so the spring stiffness has significant effect on water hammer when the valve closes. Fig. 7 shows the pressure shock values under three different spring stiffnesses, $k_{2}=3 \mathrm{~N} / \mathrm{mm}, k_{2}=4.3 \mathrm{~N} / \mathrm{mm}, k_{2}=6.6 \mathrm{~N} /$ $\mathrm{mm}$. It is clear that the simulation results agree well with the experimental results in these three conditions, so it can be concluded that the mathematic model proposed is proper to calculate the pressure shock. It can be seen that the corresponding testing values are $15_{+3.2-3.0} \mathrm{MPa}, 15_{+6.5-4.5} \mathrm{MPa}$ and $15_{+8.8-7.3} \mathrm{MPa}$ in the three conditions. The overshoots of the pressure are $21.3 \%, 43.3 \%$, and $58.7 \%$, respectively. In other words, the pressure fluctuation becomes stronger when the spring stiffness increases. The reason for this is revealed from Fig. 8, which shows the displacement curves of the valve under different spring stiffnesses. Regions $\mathrm{m}, \mathrm{n}$, and $\mathrm{p}$ represent the end stages of the closing process of the valve under different spring stiffnesses. It is obvious that the absolute slope value of the displacement curve on region $\mathrm{n}$ is higher than that of region $\mathrm{m}$; in other words, the closing speed of the valve with $k_{2}=4.3 \mathrm{~N} / \mathrm{mm}$ is bigger than that of the valve with $k_{2}=3 \mathrm{~N} / \mathrm{mm}$. However, the valve becomes unstable when the spring stiffness continues to increase to $6.6 \mathrm{~N} / \mathrm{mm}$, especially for area $\mathrm{p}$. In this case, the pressure fluctuation does not result from the rapid closure of the valve but due to the vibration of the valve. Above all, small spring stiffness is good for the stability of the valve and suppressing water hammer.

\subsection{Effects of the Throttle Window}

Three valve spools with different throttle windows are designed and manufactured. The water hammer of these valves is simulated and tested. The corresponding results are displayed in Fig. 9. It is clear that the simulation results are close to the corresponding experimental results of the three valves with different throttle windows. The valve with a round window produces the highest shock, which reaches $24.2 \mathrm{MPa}$; the overshoot of the hydraulic shock is $61.3 \%$. However, the valve with the rectangle-combined window and the one with the triangular window produce nearly the equivalent pressure fluctuations. The peak values are 19.3 MPa and $18.3 \mathrm{MPa}$, respectively, and the corresponding overshoots are $28.7 \%$ and $22 \%$. Therefore, the valve spool with a triangular window produces the lowest hydraulic shock due to its smallest area gain. Fig. 10 gives the testing pressure results of the valve spool with a triangular window and the present poppet valve, which is also manufactured and tested. It is clear that the water hammer induced by the valve with the triangular window is much weaker than that of the traditional poppet valve. The peak pressure value induced by the valve with the triangular window, 18.2 $\mathrm{MPa}$, is $39.1 \%$ lower than $29.9 \mathrm{MPa}$, which is the highest value of the poppet valve.

\subsection{Effects of the Opening and Closing Process}

The water hammer induced by the large flow directional valve causes damage to the system, so it should be reduced to ensure safety. Furthermore, with the increasing demand and the triangular window valve of automation in the coal mine, the posture of the hydraulic support must be adjusted and controlled precisely according to the roof situations. Fortunately, electro-hydraulic proportional control is a proper 


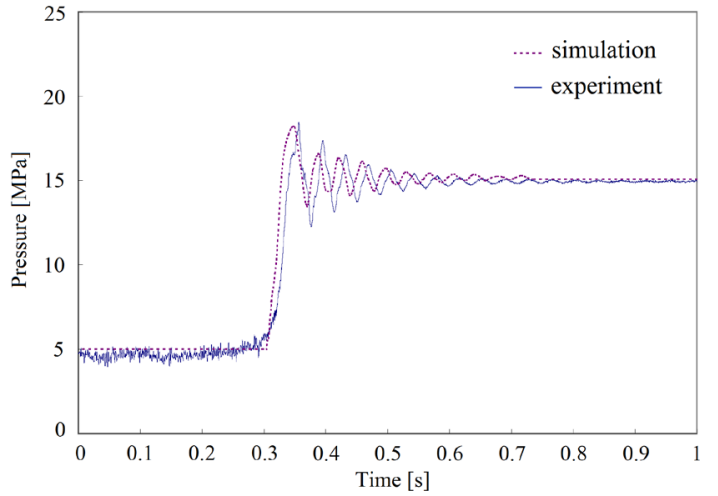

a)

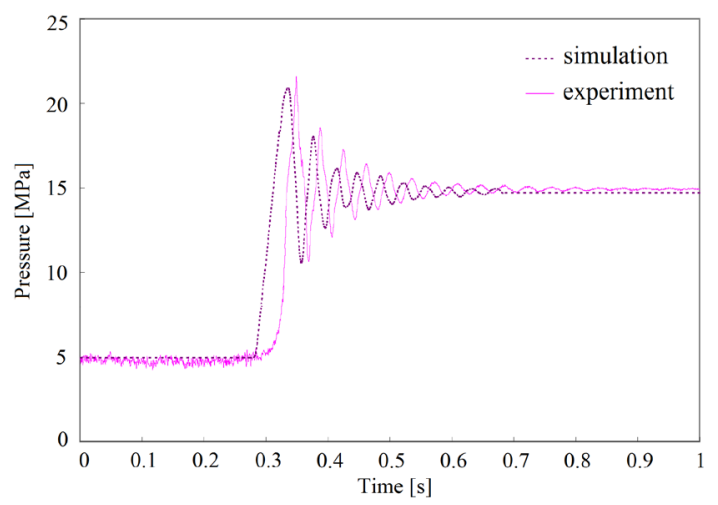

b)

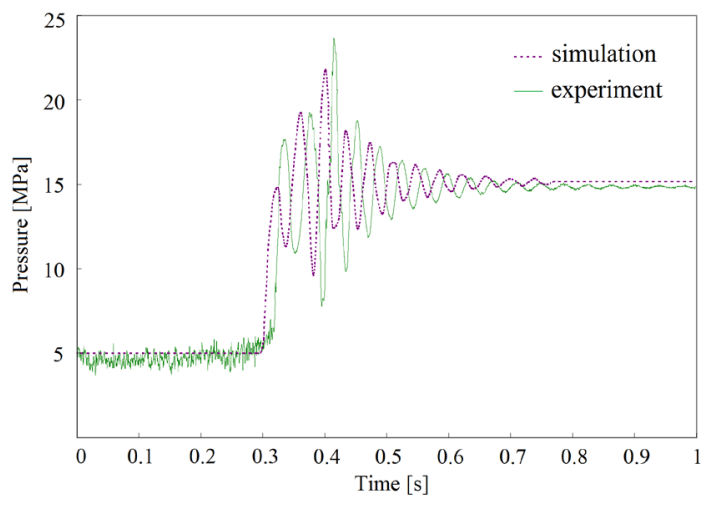

Fig. 7. Pressure shock of the valve with different spring stiffnesses for a) $k_{2}=3 \mathrm{~N} / \mathrm{mm}$, b) $k_{2}=4.3 \mathrm{~N} / \mathrm{mm}$, and c) $k_{2}=6.6 \mathrm{~N} / \mathrm{mm}$

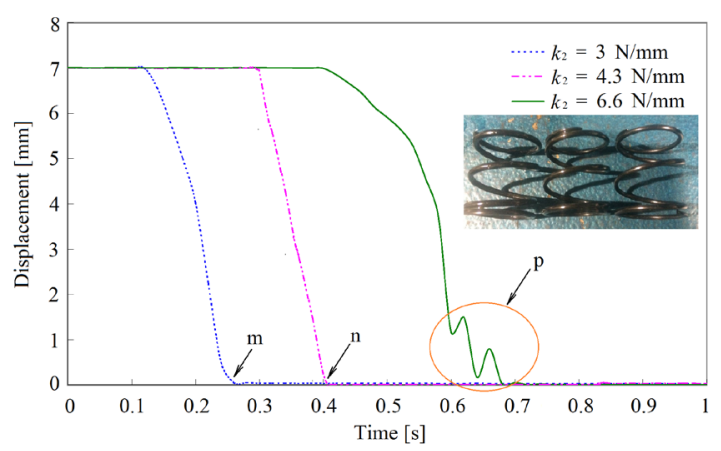

Fig. 8. Displacement curves of the valve with different spring stiffnesses

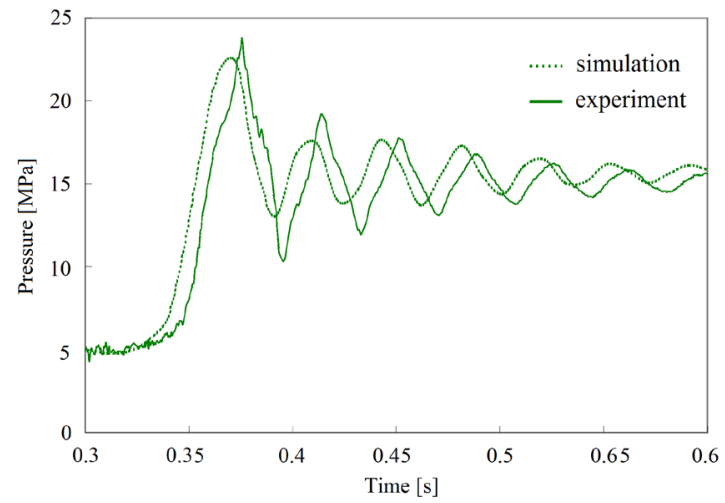

a)
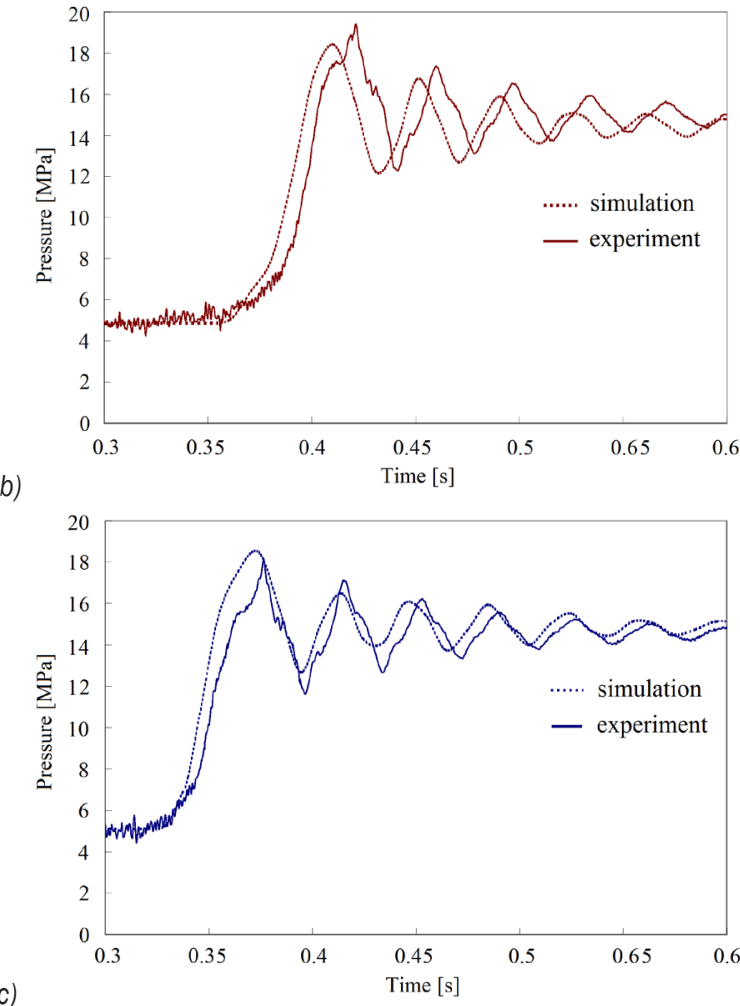

Fig. 9. Pressure shock of the valve with different throttle window; a) round, b) rectangle-combined and c) triangular window

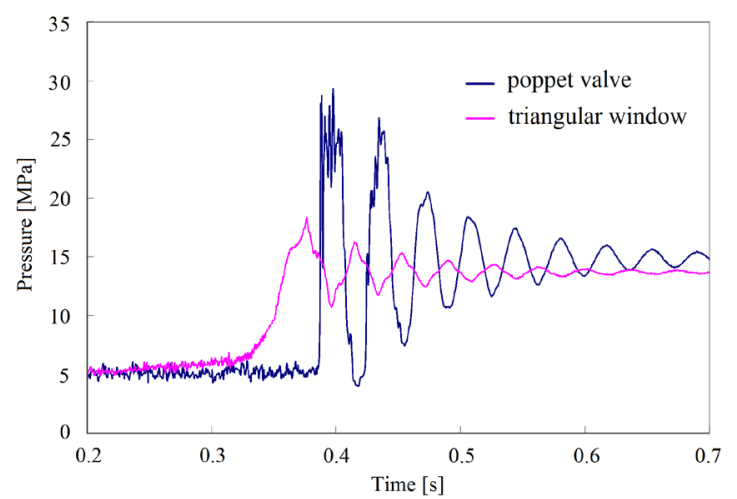

Fig. 10. Testing results of the poppet valve 
method to solve these two issues. Therefore, the present on/off valve is developing in the direction of proportional control, that is to say, the valve can be operated by the desired opening and closing process. Fig. 11 shows the displacement curves of the three designed straight lines for the main control valve, and the closing time is $100 \mathrm{~ms}, 200 \mathrm{~ms}$ and 300 $\mathrm{ms}$, respectively. Fig. 12 shows the corresponding pressure curves of the valve. It can be seen that when the closing time is $100 \mathrm{~ms}$, the pressure ranges from 11.8 $\mathrm{MPa}$ to $21 \mathrm{MPa}$, and the corresponding overshoot is $40 \%$. When the closing time extends to $200 \mathrm{~ms}$, the peak pressure drops to $19.5 \mathrm{MPa}$, and the maximum overshoot is $30 \%$, reduced by $10 \%$ compared with that of the $100 \mathrm{~ms}$ case. The peak pressure drops to 18.5 MPa when the time extends to $300 \mathrm{~ms}$, and the corresponding maximum overshoot is only $2 \%$.

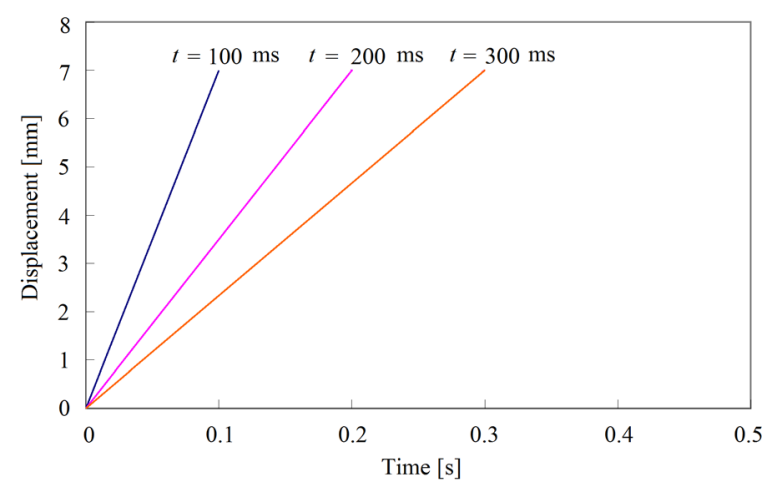

Fig. 11. Three designed straight lines for the main control valve

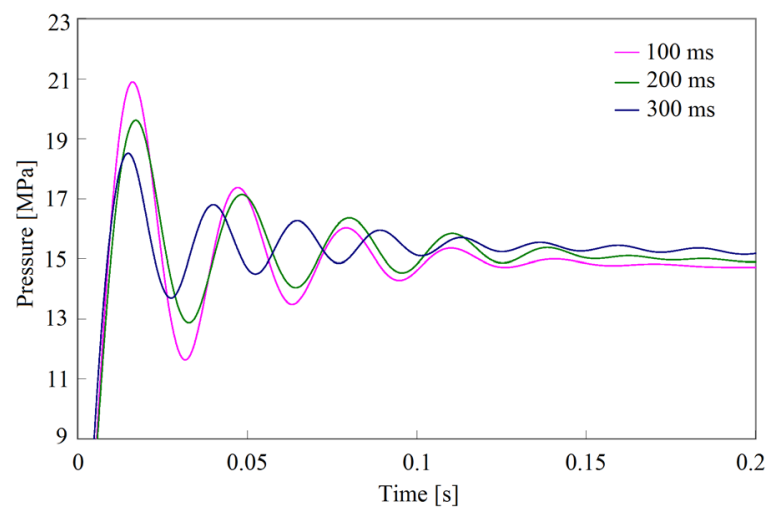

Fig. 12. Pressure under three different closing time

Fig. 13 shows three different control curves of the main valve. They are the straight line, parabolic line, and $\mathrm{S}$ line; all the opening and closing time of them is $300 \mathrm{~ms}$. The equations of the three different control curves are listed below.

$$
x=\left\{\begin{array}{lr}
\frac{70}{3} t & \text { (straight line) } \\
\frac{700}{9} t^{2} & \text { (parabola line) } . \\
\frac{7}{1+e^{-40(t-0.22)}} & \text { (S line) }
\end{array}\right.
$$

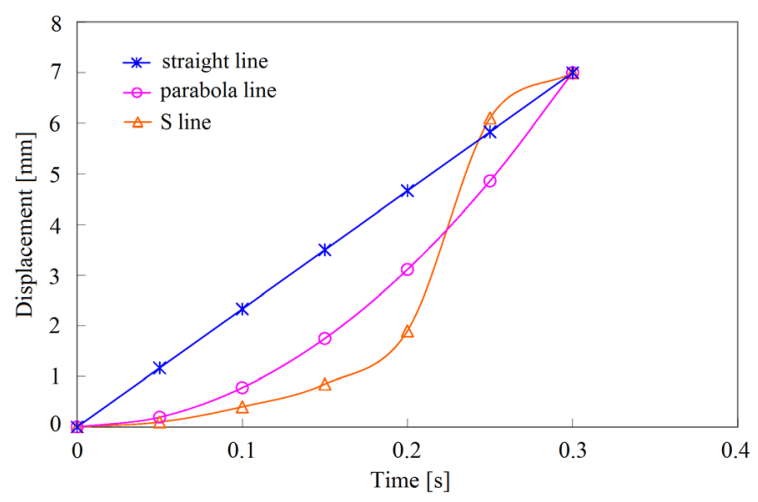

Fig. 13. Three different kinds of control curve for the main control valve

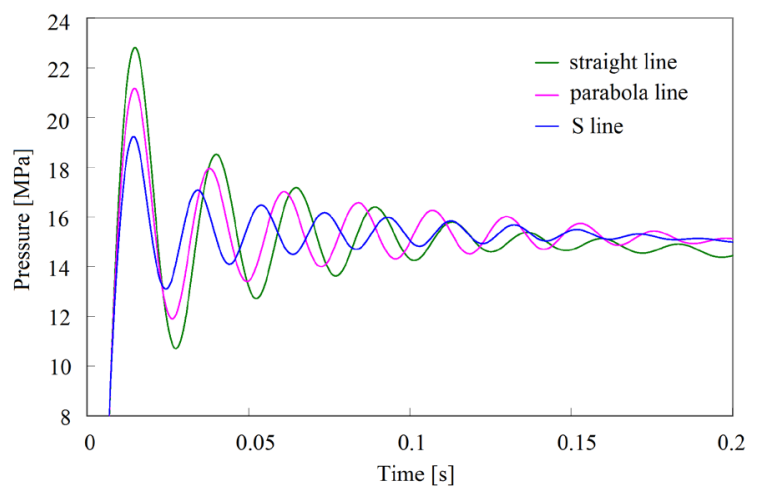

Fig. 14. Pressure under three different kinds of control curve

Fig. 14 is the corresponding pressure curves of the valve. It can be seen that the peak value and the pressure range value are all the greatest under the straight line. The corresponding pressure ranges from 23.1 $\mathrm{MPa}$ to $12 \mathrm{MPa}$, and the maximum overshoot is $54.7 \%$. Regarding the parabolic line, the pressure peak value is $21.3 \mathrm{MPa}$, and the overshoot is $42 \%$, reduced by $12.7 \%$ compared to that of the straight line. This is because the slope (which represents the velocity) of the parabolic line is smaller than that of the straight line at the initial small opening stage. If the main valve opens and closes according to the $\mathrm{S}$ line, the maximum pressure is $19.2 \mathrm{MPa}$, and the overshoot is $28 \%$, reduced by $26.7 \%$ compared with that of the straight line. It is obvious that the pressure shock under the $\mathrm{S}$ line is lower than that of 
the parabolic line due to the smaller slope of the S line in the opening stage. Furthermore, in the middle stage of the $\mathrm{S}$ line, the much bigger slope, which represents the greater velocity of the valve spool, can make the valve reach the largest flow quickly. In addition, in the end stage of the $\mathrm{S}$ line, the slope is becoming smaller gradually, so not only the mechanical shock between the spool and the sleeve but also the water hammer can be weakened.

\section{DISCUSSIONS AND CONCLUSIONS}

Hydraulic support not only provides safe spaces for the workers and equipment but also achieves a variety of actions for automation in the coal mine. Water hammer induced by the water directional valve used on the hydraulic support occurs easily due to the highpressure stiffness of water, causing great damage to the safety of workers and equipment. To suppress it, a plane-sealed large flow directional valve with different throttle windows is designed. First, the shape of the throttle window is taken into consideration when the model of the valve is established; then the shape of the throttle window and the spring stiffness are optimized to reduce the pressure shock. Last, the effects of the opening and closing processes of the main valve on the water hammer are explored, providing significant references for future electro-hydraulic proportional control of the large flow water directional valve.

In summary, the innovations and contributions of this paper are:

1) The shape of the throttle window must be considered when the model of the valve is established. Different throttle windows have different area gains and flow gains, resulting in different water hammer values. The common round throttle window produces the largest pressure shock because of its biggest area gain under the same conditions, followed by the rectangle-combined window and the triangular window. The triangular window produces the smallest pressure shock. The maximum overshoot of the pressure shock was reduced by $39.3 \%$ compared with that of the round one. Furthermore, the pressure peak value of the valve with the triangular window is $39.1 \%$ lower than that of the present poppet valve.

2) The reasons the water hammer differs under different spring stiffnesses. When the spring stiffness is small, it affects the closing speed of the valve spool, thus affecting the pressure shock. To some extent, the bigger the spring stiffness is, the faster the valve closes, and the greater pressure shock is produced. If the spring stiffness increases to $6.6 \mathrm{~N} / \mathrm{mm}$, the pressure shock continues to increase; however, it is no longer due to the rapid closure of the valve, but because of the unstable oscillation of it. Consequently, the spring with small stiffness is helpful for suppressing the pressure shock and good for the stability of the valve.

(3) Controlling the opening and closing process of the main valve can effectively reduce water hammer. It can be carried out through two ways: one is extending the closing time, and the other is adjusting the control curve. The essence of the two methods is lowering the opening and closing speed of the main valve, but the former is to make the whole process slow down while the latter is to slow down the local speed of the valve. Compared with that of the straight line and the parabolic line, the water hammer induced by the valve under the $\mathrm{S}$ line is the lowest because the speed of the valve in the small opening stage is the smallest. Furthermore, in the middle stage of the $\mathrm{S}$ line, the bigger velocity of the valve spool can make the valve reach the highest flow quickly. In addition, in the end stage of the S line, the speed is becoming smaller gradually, so not only the mechanical shock between the spool and the sleeve but also the pressure shock can be significantly weakened.

\section{ACKNOWLEDGEMENTS}

The authors thank the support of Shanxi Science and Technology Department, under project numbers 201701D221139 and MJ2014-07. We also thank the support of the National Natural Science Foundation of China, under project number U1610251.

\section{NOMENCLATURE}

$m_{1}$ mass of the pilot valve spool, [kg]

$m_{2}$ mass of the inlet valve spool, [kg]

$l$ propagation distance along pipeline, $[\mathrm{m}]$

$x_{1}$ displacement of the pilot valve spool, [m]

$x$ displacement of the main control valve, $[\mathrm{m}]$

$c_{f 1}$ viscous friction coefficient of the pilot valve spool, $[\mathrm{N} \cdot \mathrm{s} / \mathrm{m}]$

$c_{f 2}$ viscous friction coefficient of the inlet valve spool, $[\mathrm{N} \cdot \mathrm{s} / \mathrm{m}]$

$k_{1} \quad$ spring stiffness of the pilot valve, [N/m]

$k_{2} \quad$ spring stiffness of the main control valve, [N/m]

$F_{p 1}$ press force on the pilot valve, [N]

$F_{p 2}$ press force on the inlet valve spool, [N] 
$F_{w 1}$ steady flow force on the pilot valve, [N]

$F_{w 2}$ steady flow force on the inlet valve spool, [N]

$F_{10}$ pre-compression force of the pilot valve spring, $[\mathrm{N}]$

$F_{20}$ pre-compression force of the main control valve spring, $[\mathrm{N}]$

$F_{m}$ coulomb friction force of the valve spool, [N]

$F_{d}$ output force of the solenoid valve, [N]

$t$ time, [s]

$q_{1}$ flow rate of the pilot valve, [1/min]

$q_{2}$ flow rate of the fixed orifice, [1/min]

$Q_{x}$ flow rate through the throttle window, [1/min]

$K_{q x}$ flow gain of the main control valve, $[1 /(\mathrm{min} / \mathrm{m})]$

$A_{p 1}$ flow area of the pilot valve port, $\left[\mathrm{m}^{2}\right]$

$A_{p 2}$ flow area of the fixed orifice, $\left[\mathrm{m}^{2}\right]$

$A(x)$ flow area of the throttle orifice, $\left[\mathrm{m}^{2}\right]$

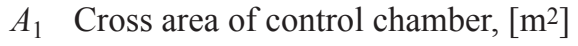

$C_{q 1}$ flow coefficient of the pilot valve port, [-]

$C_{q 2}$ flow coefficient of the fixed orifice, [-]

$C_{q}$ flow coefficient of the throttle orifice, [-]

$p$ pressure in the pipeline, $[\mathrm{Pa}]$

$p_{1}$ output pressure of the pilot valve, $[\mathrm{Pa}]$

$p_{2}$ pressure in the control chamber, [Pa]

$p_{z} \quad$ outet pressure of the main control valve, $[\mathrm{Pa}]$

$V$ longitudinal mean velocity in the pipeline, $\left[\mathrm{m}^{3}\right]$

$V_{1}$ volume of the control chamber of the main control valve, $\left[\mathrm{m}^{3}\right]$

$\beta$ bulk modulus of the fluid, [Pa]

$\delta \quad$ buffer damp gap on one side, [m]

$\mu \quad$ dynamic viscosity of the liquid, $[\mathrm{Pa} \cdot \mathrm{s}]$

$\rho$ density of the liquid, $\left[\mathrm{kg} / \mathrm{m}^{3}\right]$

$H$ pressure head in the pipeline, [m]

$f \quad$ Friction factor, [-]

$D$ diameter of the pipeline, [m]

$g$ gravitational acceleration, $\left[\mathrm{m} / \mathrm{s}^{2}\right]$

$a$ propagation speed of the shock wave, $[\mathrm{m} / \mathrm{s}]$

$\theta \quad$ angle between the axis and the horizontal line, $\left[{ }^{\circ}\right]$

\section{REFERENCES}

[1] Wang, G., Pang, Y. (2015). Relationship between hydraulic support and surrounding rock coupling and its application. Journal of the China Coal Society, vol. 40, no. 1, p. 30-34, D0I:10.13225/j.cnki.jccs.2013.1704. (in Chinese).

[2] Yang, H., Zhou, H. (2002). Some key problems of the water hydraulics. Chinese Journal of Mechanical Engineering, vol. 38, p. 96-100, D0l:10.3901/JME.2002.supp.096. (in Chinese)

[3] Yang, H., Gong, Y., Zhou, H. (2006). Study on water hydraulic directional valve with plane piston structure. Journal of Zhejiang University (Engineering Science), vol. 40, no. 3, p. 408-413. (in Chinese)

[4] Liao, Y., Yuan H., Lian Z., Feng, J., Guo, Y. (2015). Research and analysis of the hysteresis characteritics of a large flow directional valve. Strojniski vestnik - Journal of Mechanical
Engineering, vol. 61, no. 6, p. 355-364, D0l:10.5545/svjme.2015.2487.

[5] Qiu, Y., Li, B., Fu, X., Yang, G., Hu., J. (2014). Suppressing water hammer of ship steering systems with hydraulic accumulator. Proceedings of the Institution of Mechanical Engineers Part E: Journal of Process Mechanical Engineering, vol. 228, no. 2, p. 136-148, Dol:10.1177/0954408913488770.

[6] Galbally, D., Garcia, G., Hernando, J., de Dios Sánchez, J., Barral, M. (2015). Analysis of pressure oscillations and safety relief valve vibrations in the main steam system of a boiling water reactor. Nuclear Engineering and Design, vol. 293, p. 258-271, D0l:10.1016/j.nucengdes.2015.08.005.

[7] Zhang, Z., Zhou, H., Gao, Y ., Chen, Y. (2009). Simulation and experiment on static characteristic of water hydraulic proportional pressure relief valve. Journal of the China Coal Society, vol. 34, no. 11, p. 1569-1573. (in Chinese)

[8] Xu, H., Guang, Z.M., Qi, Y.Y. (2011). Hydrodynamic characterization and optimization of Contra-push check valve by numerical simulation. Annals of Nuclear Energy, vol. 38, no. 6, p. 1427-1437, Dol:10.1016/J.anucene.2011.01.013.

[9] Adamkowski, A., Lewandowski, M. (2014). Cavitation characteristics of shutoff valves in numerical modeling of transients in pipelines with column separation. Journal of Hydraulic Engineering, vol. 141, no. 2, p. 1-10, Dol:10.1061/ (ASCE)HY.1943-7900.0000971.

[10] Liu, Z., Zhu, Q., Yang W., Li, Y. (2015) Transient characteristics of double-suction centrifugal pump during starting period under shut-off condition. Transactions of the Chinese Society for Agricultural Machinery, vol. 46, no. 10, p. 44-48, DOI:10.6041/J.issn.1000-1298.2015.10.007.

[11] Kou, Y., Yang, J., Kou, Z. (2016). A water hammer protection method for mine drainage system based on velocity adjustment of hydraulic control valve. Shock and Vibration, vol. 2016, art. ID 2346025, DOl:10.1155/2016/2346025.

[12] Yao, E., Kember, G., Hansen, D. (2015). Analysis of water hammer attenuation in applications with varying valve closure times. Journal of Engineering Mechanics, vol. 141, no. 1, p. 1-9, DOI:10.1061/(ASCE)EM.1943-7889.0000825.

[13] Wan, W., Li, F.Q. (2015). Sensitivity analysis of operational time differences for a pump-valve system on a water hammer response. Journal of Pressure Vessel Technology, vol. 138, no. 1, D0I:10.1115/1.4031202.

[14] Kaliatka, A., Vaišnoras, M., Valinčius, M. (2014). Modelling of valve induced water hammer phenomena in a district heating system. Computers \& Fluids, vol. 94. p. 30-36, D0l:10.1016/j. compfluid.2014.01.035.

[15] Karadžić, U., Bulatović, V., Bergant, A. (2014). Valve-induced water hammer and column separation in a pipeline apparatus. Strojniški vestnik - Journal of Mechanical Engineering, vol. 60, no. 11, p. 742-754, D0l:10.5545/sv-jme.2014.1882.

[16] Yang, S., Wu, D., Lai, Z., Du, T. (2017). Three-dimensional computational fluid dynamics simulation of valveinduced water hammer. Proceedings of the Institution of Mechanical Engineers, Part C: Journal of Mechanical Engineering Science, vol. 231, no. 12, p. 2263-2274, Dol:10.1177/0954406216631780.

[17] Amirante, R., Distaso, E., Tamburrano, P. (2016). Sliding spool design for reducing the actuation forces in direct operated 
proportional directional valves: Experimental validation. Energy Conversion and Management, vol. 119, p. 399-410, DOl:10.1016/j.enconman.2016.04.068.

[18] Lisowski, E., Filo, G. (2016). CFD analysis of the characteristics of a proportional flow control valve with an innovative opening shape. Energy Conversion and Management, vol. 123. p. 1528, DOI:10.1016/j.enconman.2016.06.025.
[19] Lisowski, E., Grzegorz Filo, G., Rajda, J. (2018). Analysis of flow forces in the initial phase of throttle gap opening in a proportional control valve. Flow Measurement and Instrumentation, vol. 59. p. 157-167, D0l:10.1016/j. flowmeasinst.2017.12.011. 